Journal of Advanced Research in Fluid Mechanics and Thermal Sciences

\title{
Measurement of Neutron Flux at Thermal Column Using Gold Foil Activation Analysis and TLD Detector: Technical Review
}

\author{
Safwan Shalbi ${ }^{1}$, Norazlianie Sazali ${ }^{1,2,}{ }^{*}$, Wan Norharyati Wan Salleh ${ }^{3}$ \\ 1 College of Engineering, Universiti Malaysia Pahang, Lebuhraya Tun Razak, 26300 Gambang, Kuantan, Pahang, Malaysia \\ 2 Centre of Excellence for Advanced Research in Fluid Flow (CARIFF), Universiti Malaysia Pahang, Lebuhraya Tun Razak, 26300 Gambang, Kuantan, \\ Pahang, Malaysia \\ 3 Advanced Membrane Technology Research Centre (AMTEC), School of Chemical and Energy, Faculty of Engineering, Universiti Teknologi \\ Malaysia, 81310 Skudai, Johor Darul Takzim, Malaysia
}

\section{ARTICLE INFO}

\section{Article history:}

Received 31 January 2021

Received in revised form 5 May 2021

Accepted 10 May 2021

Available online 1 June 2021

\section{ABSTRACT}

The thermal column at the TRIGA PUSPATI (RTP) research reactor can produce thermal neutron. However, the optimization on the thermal neutron flux produced should be performed to gain a sufficient thermal neutron for boron neutron capture therapy purpose. Thus, the objective of this review is to optimize the thermal neutron flux by designing the collimator with different materials at the thermal column. In order to fulfil the requirement, set by the IAEA standard, the study of Boron Neutron Capture Therapy (BNCT) around the world was being reviewed to study the suitable measurement, material, design, and modification for BNCT at the thermal column of TRIGA MARK-II, Malaysia. Initially, the BNCT mechanisms and history was review. Then, this paper review on the design and modifications for BNCT purpose around the world. Based on this review, suitable material and design can be used for the BNCT in Malaysia. Moreover, this paper also reviews the current status of BNCT at the RTP with the measurement of the thermal neutron flux was conducted along the thermal column at $250 \mathrm{~kW}$. The thermal column of RTP was divided into 3 phases (Phase 1, Phase 2 and Phase 3 ) so that an accurate measurement can be obtained by using gold foil activation method. This value was used as a benchmark for the neutron flux produced from the thermal column. The reviewed demonstrated that the final thermal neutron flux produced was significantly for BNCT purpose.

neutron flux; thermal neutron; BNCT;

Triga Mark-II

\section{Introduction}

BNCT is one of the promising methods in order to cure cancer by using neutron source either from nuclear research reactor or neutron generator such as an accelerator. BNCT method used the combination of low energy of neutron (slow neutron) irradiation and the targeting of a tumour site injected with a proper boron containing compound. Basically, the tumour cell was not directly destructed by neutron, but indirectly destroyed by the results of nuclear reaction between neutron and boron. In theory, the BNCT also is one of the forms of radiotherapy which is selectively kills the

\footnotetext{
* Corresponding author.

E-mail address: azlianie@ump.edu.my
}

https://doi.org/10.37934/arfmts.83.2.2543 
cancer cells and less effect on other normal cell that used photon that will selectively deposited in tumour cell of boron carriers such as BPA and BSH. The standard boron carries compound must be enriched by Boron-10 about $20 \%$ natural abundance. The patient will be irradiated with slow energy of neutron to reach the ratio of high concentration of boron in the tumour cell [1]. The irradiation with slow neutron points out of nuclear reaction that form the products of Boron-10 capture the thermal neutron and as a result of production Boron-10 convert into Boron-11 which decay from the emission of an alpha particle [2].

In general, most of the BNCT studies use neutron source from the research reactors. This research is aimed at developing a BNCT facility for the cancer treatment studies that is safe and controlled from radiation over exposure and practically uses slow neutrons emitted from the Malaysian TRIGA MARK II reactor. Thus, the first step in order to achieve the long-term goal of this project is to establish the suitability of neutron fluxes produced from the research reactor [3]. Commonly, most of the TRIGA reactor has a thermal column facility, which is comprises of graphite moderator designed to produce epithermal neutrons and thermal neutrons which can be utilised in BNCT facility. Therefore, the thermal column of Malaysian TRIGA MARK II reactor was identified for BNCT study as it has thermal and epithermal neutron source for this research. Previous researches indicated that the thermal column in the Malaysian TRIGA MARK II reactor has a sufficient a quality neutron beam to develop BNCT facility [4]. In order to develop a BNCT facility at the thermal column at this reactor, neutron measurement needs to be carried out comprehensively in the thermal column (graphite), thermal column door and outside of the thermal column to produce benchmark for material to be used for collimator and shielding this research [5].

\section{BNCT Historical and Review}

Initially in BNCT, thermal neutron is captured by Boron-10 and becomes unstable because of its properties towards neutron. Neutron, especially thermal neutron was well known for its neutral properties (no electrical charge) and could be absorbed by atomic nuclei which collide with it to create heavier isotope. The unstable reaction of Boron-10 and thermal neutron results of emitting both high LET (Linear Energy Transfer) $\alpha$ and $\gamma$ before it changes to Lithium-7. The LET is a term that used to measure the force acting on a charged particle travelling through matter [6]. There are three factors affecting LET which is charge, velocity and the mass of the particle [7]. BNCT emitted both high LET $\alpha$ and $\gamma$ which have deeper penetration in the range of $\sim 10 \mu \mathrm{m}$ which is approximately to the diameter of mammalian cell and promptly attenuating the radiation [8]. Hence, the BNCT give a highly localized treatment to the tumour cell compare to other treatment. The basic nuclear reaction is illustrated in Figure 1.

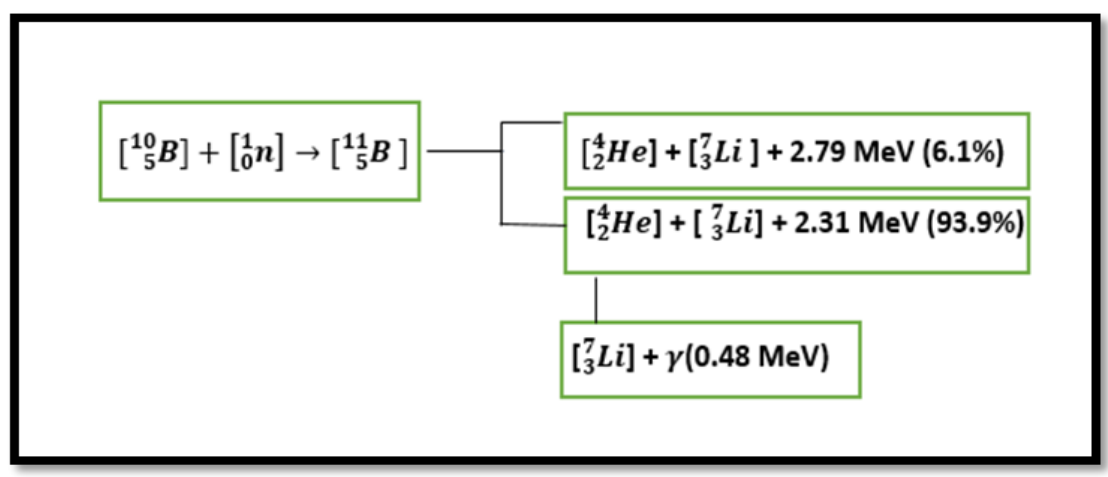

Fig. 1. Neutron capture by the boron and subsequent nuclear reaction and nuclear fission [9] 
After several years of disclosure of neutron by James Chadwick in 1932, Locher was firstly proposed the concept of neutron capture therapy [10]. Locher discovered the availability of slow neutron capture with the high cross section naturally occurring isotope B-10 because of its properties that have high avidity in absorbing slow neutron. This is the initially described the BNCT in 1936 [11]. According to Chen [12], the uses of boron in BNCT was because of the properties of boron was highly selectively absorb by malignant tumour cells and it was mainly proposed of the destruction of cancer cells only. In theory, if boron could be selectively concentrated in a tumour and the volume then exposed to thermal neutrons, a higher radiation dose to the tumour relative to adjacent normal tissue would result [13]. This persuade the first clinical trials of BNCT in year 1950s-1960s using thermal neutron at Massachusetts General Hospital (MGH) and at the Brookhaven National Laboratory (BNL) and the trials were to identify the significant of the BNCT as an efficiency therapeutic treatment. The first clinical trial was considered as a failure because of the insufficient beam penetration but to curtail this problem, other trials was conducted at the Massachusetts Institute of Technology Research Reactor (MITR-I) with maximum surgical of the tumour's precedent to BNCT. As the early stage of BNCT trials, there is no evidence of any survival using BNCT [14].

One of the challenges to enhance BNCT during those years is to develop and improve the new boron compound to achieve suitable tumour to brain concentration. Initially, in the early stage of BNCT studies, sulfhydryl-polyhedral borane (BSH) and borated phenylalanine (BPA) were used to improve the tumours to boron concentration ratio. This study was conducted by Dr Hatanaka, a neurosurgeon from Japan who being the apprentice to Dr Sweet at MGH (Massachusetts General Hospital) in 1968 after he returned to Japan. By using the BSH as a boron carrier, Dr Hatanaka had performed the open skull irradiation of the brain tumours using slow neutron [15]. After the success of the experiment in Japan, there are several groups of researchers working of BNCT using BSH for the brain tumour and as a result there are about 200 patients being treated with this technique with encouraging result [15]. At the same time, Dr Mishima a researcher from Japan also that working on borated phenylalanine (BPA) for treat malignant melanoma. Based on the documentation of $\mathrm{Dr}$ Mishima clinical trial and experiment on BNCT using BPA recorded that the normal skin of human is very response towards the BNCT treatment for malignant melanoma. In 1993, the beam use for BNCT had been more focus on intermediate neutron beam or epithermal neutron compared to the thermal neutron beam. The epithermal neutron was believed to have more penetration that can help in reducing the scalp reaction without having any complications. The MITR-II becomes the first who conducted the BNCT using the epithermal neutron to the human in 1994. The use of epithermal neutron for BNCT also had being widely use at the same time when the BMRR reactor apply to clinical trial for central nervous system tumours [14].

In Finland, the BNCT was conducted at the TRIGA MARK II type FiR1 reactor. The patients are intravenous administered with BPA-F as a boron carrier and was irradiated with the use of epithermal neutron without having other surgical procedures [16]. For the BNCT purpose, the neutron moderator material use is FLUENTAL which are the combination of $69 \%$ of AlF3, $30 \%$ of metallic $\mathrm{Al}$ and $1 \%$ of LiF7. For the shield purpose bismuth was used to shield low gamma, thermal neutron and fast neutron contamination. The uses of the epithermal neutron beam for BNCT have been confirmed by the Finnish dosimetry team and verified by Idaho National Laboratory, Nuclear Research Institute (NRI) Republic of Czech and also Massachusetts Institute of Technology (MIT). The advantage of using the TRIGA reactor for BNCT purpose is the stability and the availability to produce and supply the high neutron intensity with the low radiation background of the treatment beam. The clinical trials using TRIGA reactor had been done also at Europe, Japan and USA and none of the BNCT was postponed or cancel due to the reactor problem. The result of BNCT by using TRIGA reactor had 
convince the construction of BNCT for MARIA research reactor at the Institute of Atomic Energy at Swierk [17].

Despite of the research in BNCT by mostly government sector around the world, there are one private health company had looked forward of BNCT which is Boneca. According to Pohjola [8], the Boneca had proved their passion on BNCT by proved that the BNCT can be used to treat the head and neck cancer more beneficial compare to the conventional therapy. In fact, in 2007 there are clinical trials on 12 patients who suffering head and neck cancer with good response and result. About 7 patients had been successfully eliminated the tumour and the remaining patients had substantial tumour shrinkage with most of them have moderate adverse effect. To consider the good result, Boneca had looking forward by expand their study on BNCT for head and neck cancer for 30 more patients [18]. One of the reasons for choosing BNCT is the dose to the tumour can be increase without exceed the normal tissues tolerance [19].

In Turkey, the research of BNCT was conducted at the ITU (Istanbul Technical University) TRIGA MARK II research reactor. To produce high intensity and quality of neutron beam for BNCT purpose, the radial beam port has been modified. It has collimator from the material of polyethylene and Cerrobend installed. Cerrobend are the combination of $50 \%$ bismuth, $31.8 \%$ of lead and $18.2 \%$ of $\mathrm{Sn}$. Figure 2 shows the geometry design of Polyethylene/ Cerrobend collimator.

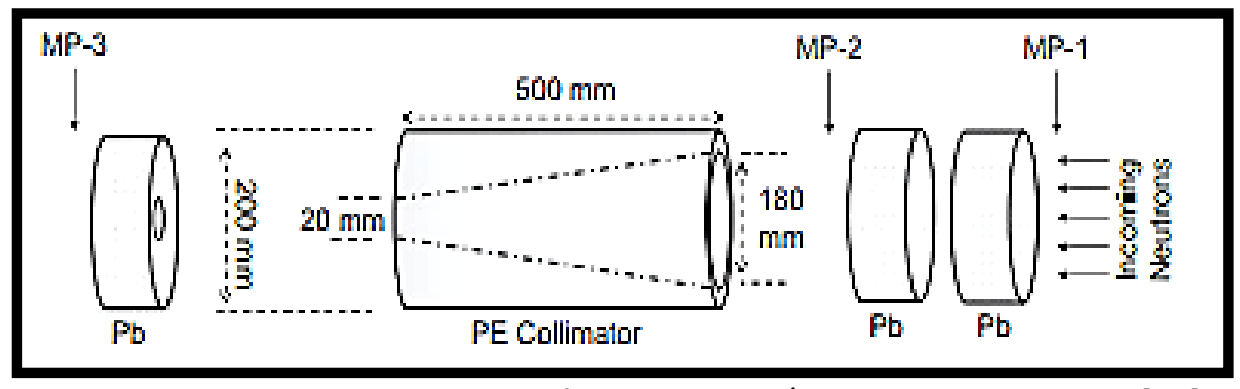

Fig. 2. Geometric characteristic of Polyethylene/Cerrobend Collimator [20]

Before installing the collimator, the initial step must be used to measure the neutron flux produced by using neutron activation analysis (Au-Cd Foils). Then the results from the neutron activation analysis was used to verified using MCNP (Monte Carlo Neutron Particle) simulation. The used of polyethylene as collimator is good to reduce the slow neutron while the Cerrobend is more efficient to provide and produces the epithermal neutron [20]. Despite the use of research reactor as the neutron source for BNCT, the accelerator facility also is recognized as a neutron source. The accelerator is a machine that can be used to accelerate proton to the required energy for the reaction and results of neutron emitted at the energy range appropriate for BNCT [15]. The advantages of using accelerator are easy to operate, required less people to handle it compares to the research reactor, less overall risk than reactor and cheaper. The accelerator can be classified based on the range of low energy electrostatics machines to the higher energy cyclotrons. This accelerator however produces high energy neutron energy which is beyond the BNCT limit. Thus, the use of accelerator as a neutron source needs the brute force moderation or large moderator assemblies for specifically obey the neutron specification for BNCT [21].

There are several studies around the world, including Argentina, Italy, Japan, Russia, United Kingdom and Israel regarding to development of AB-BNCT (accelerator base BNCT). The studies of the accelerator around the world consider on the different type of accelerator and the nuclear reaction. In Argentina for example, they investigated on the ${ }^{13} C(d, n){ }^{14} N$ reaction as a neutron source for BNCT while in United Kingdom the reaction of ${ }^{7} \operatorname{Li}(p, n){ }^{7} \mathrm{Be}$ are being studied as a neutron source to produce an epithermal neutron source for BNCT [22]. In terms of nuclear reaction, 
it can be divided into two different type which is endothermic reaction and exothermic reaction. The study on ${ }^{9} \mathrm{Be}(d, n){ }^{10} \mathrm{~B}$ reaction show that the ${ }^{9} \mathrm{Be}$ have advantages on thermo-mechanical properties ${ }^{7} \mathrm{Li}$ because it can lead the stabilization of residual products. Hence, become the advantages for hospitality-based facility because the ${ }^{9} \mathrm{Be}(d, n){ }^{10} \mathrm{~B}$ can be utilized about $1.4 \mathrm{MeV}$, which implying the smallest possible accelerator compare to others [21]. Another neutron source can be used for BNCT purpose is a sealed generator tube. The sealed generator tube is neutron generators which use the microwave ion source to produce the deuterium and tritium ions from the plasma. The mechanisms of the sealed generator tube is by the microwave ions will yield a higher fraction of monoatomic ion species in the ion beam [23]. Then the ions will accelerate to impinge the beam on the target with the energy of $14.1 \mathrm{MeV}$ D-T neutrons that are generated from the fusion reaction. In fact, the yield of the neutron can be automatically controlled by the system and can have the stable yield also. Actually, the main objective of the development of a sealed generator tube is to study the feasibility of the neutron for BNCT to cure liver tumour. In procedures, there are four sealed generator tube use and produce about $4 \times 10^{11} \mathrm{ncm}^{-2} \mathrm{~s}^{-1}$ and two directly placed on each side of the patient's liver [21].

As mentioned above, the energy produced from the sealed generate or tube was $14.1 \mathrm{MeV}$ is slightly high and cannot be used directly for destroying the tumour and the liver. Thus, the uses of neutron moderator were essential to produce the neutron energy in the intermediate form energy range. Different type of neutron moderator in the BSA (beam shaping assembly) are being provided which the neutron produce from the sealed generator tube must be passing through it to optimize the neutron for the BNCT purpose. Moreover, the direction of the neutron beam also needs to be guide and the study show that the reflector material such as lead can be used as a neutron reflector [21]. In terms of safety, the uses of the sealed generator tube as a neutron source is safer than the accelerator.

\subsection{Neutron Properties}

In In 1932, James Chadwick discovered the subatomic particle called neutron while working at the Cavendish Laboratory. Neutron with symbol $n$ or $n^{0}$ mass comparable to proton. Neutrons are neutral and not affected by the electrons in an atom or by the positive charge of the nucleus. As consequences, neutron passes through the atomic electron cloud. In short, neutrons collide with nuclei but not with the atoms [23]. The kinetic energy of the neutron was significance in determining the nature of interaction between the neutron and the nucleus. Cacuci [23], state that the interaction of neutron-nuclei will reduce the characteristic quantity of de Broglie wavelength $\lambda=\lambda / 2 \pi$ of the neutron -nucleus centre of mass system which defined

$$
\chi=\sqrt{\frac{h^{2}}{2 M E}}
$$

where $\lambda$ is the wavelength $(\mathrm{m}), M$ is the reduced mass $(\mathrm{kg}), E$ is the kinetic energy $(\mathrm{kg} \mathrm{m} 2 \mathrm{~s}-2)$ and $h$ is the Planck constant.

\subsubsection{Neutron absorption}

Neutron absorption is defined as a neutron absorbed by the nucleus forming new particles. There are four type of neutron absorption which is radioactive capture, fission, charged particle emission 
and neutron emission. The neutron reaction cross section can be used to identify the probability of the neutron reaction with the consideration of one mono-energy neutron source interact with the nucleus which end up as a neutron flux, $\varnothing$ (neutron $\mathrm{cm}^{-2} \mathrm{~s}^{-1}$ ).

Eq. (2) relate the relation of neutron flux, $\varnothing$ with $n$ (neutron $\mathrm{cm}^{-3}$ ) which is the number of neutrons per unit volume and its with neutron velocity, $v\left(\mathrm{~cm} \mathrm{~s}^{-1}\right)$.

$\varnothing=n v$

$N \cdot d x$ (nuclei $\mathrm{m}^{-3}$ ) is used when the target material contains $\mathrm{N}$ atom per unit volume have a certain width which has symbol as $d x$.

$\sigma=\frac{C}{\emptyset N \cdot d x}$

The equation above shows the neutron cross-section $\sigma$ (barns), whereas $C$ is belong to the neutron absorption (barns) [24].

\subsubsection{Neutron Shielding}

In neutron shielding determination, the consideration of neutron intensity is very important to determine the best shielding material purposely to shield unwanted neutron. The intensity equation is given as

$I_{d}=I_{o} \cdot e^{-\mu d}$

where $I_{d}$ is the final intensity of neutron after the shielding (neutron $\mathrm{cm}^{-2} \mathrm{~s}^{-1}$ ), $I_{o}$ is the initial intensity (neutron $\mathrm{cm}^{-2} \mathrm{~s}^{-1}$ ) of neutron before shielding, $d$ is shielding thickness $(\mathrm{cm})$ and $\mu$ is the neutron attenuation coefficient $\left(\mathrm{cm}^{-1}\right)$.

In the deep penetration of fast neutron, equal of the fast neutron fluence is produced and the including fast neutron deep in a hydrogenous medium. Moreover, as the neutron energy decrease, the cross section of hydrogen in the high MeV energy region increases then lead to lower-energy neutron scatter than the high energy neutron. Basically, the attenuation of fission neutron is even practically by both hydrogen medium and non-hydrogen shield. The interaction of $(n, \gamma)$ absorption cross-section of all of the medium used for shielding in the energy region was negligible and has no significant role in the removing the fast neutron because of the removed cross-section can be represent by the total fast neutron cross-section, an energy average of fission neutron and neutron scattering. Thus, to remove the cross-section is sufficient when the material used contain high hydrogen concentrations [23]. In addition, the fast neutron is attenuated very poorly with the nonhydrogenous material such as iron, lead and aluminium which is slightly used for photon shielding. Thus, the attenuation of fast neutron through this non-hydrogenous material can be neglected. The interaction between the fast neutron in the shielding design could produce the slow neutron and the intermediate neutron which also leads to the gamma production. In this research, one of the main aims is to successfully capture the gamma-ray dose at the surface of BNCT design with a proper consideration of shielding design and material. It is important to calculate and simulate the slow neutron and epithermal neutron in a shielding design for BNCT purpose.

One of the reasons for thermal neutron to be calculated is because of its properties of not being observed until the thermalization occurs. Moreover, during the process of the thermalization, the 
scattering can occur because of the addition of the fluences that become more isotropic. There is one approach that can be used in order to compute the build-up factor of low energy inside the shielding by using the combination of removal theory and multigroup diffusion theory. The combination of both theories, removal theory that defined as the penetration of fast neutron and multi-group diffusion theory which describe the subsequent thermalization and thermal diffusion lead to the contribution of the total dose at the shielding surface by the capture the gamma particle produced deep in the shielding and as a result of neutron absorption [23].

\subsubsection{Neutron Collimator}

In this review, the most important part to be developed and studied is collimator. Collimator are well known as a beam limiting device that widely used in various industries including optical, medical and nuclear. Its acts as a filter of the beam allowing the beam in the specific direction to travel trough. In BNCT, the collimator inside the shielding purpose was to reflect the neutrons back into the beam [24]. In large neutron source such RTP, the neutron collimator important to reduce the neutron and gamma flux for specific purposes such as BNCT, neutron radiography, diffractometer and other application that use direct neutron source from the RTP. There are three common types of neutron collimator that widely used, namely are pinhole collimator, Soller collimator and divergent collimator. The neutron collimator must be properly design for the BNCT research facility. The thermal neutron flux emitted from the collimator used for BNCT must have good quality beam with the high intensity as required by IAEA standard. The use of collimator will avoid the over exposed of the thermal neutron, fast neutron, epithermal neutron and gamma ray to the patient. In order to design suitable collimator for BNCT research facility, the parameter of L/D ratio must be considered. The $L / D$ is defined as the degree of divergence of the neutron beam where $L$ stands for the length of the collimator while $D$ is the diameter of the entrance aperture [23]. To build the collimator, the combination of neutron collimator material, neutron shielding material and neutron moderator material specification are very important. In order to obtain these specifications, a simulation based on Monte Carlo N-Particle Transport Code (MCNP) method can be used to generate the suitable parameters for neutron collimator.

\subsubsection{Neutron Moderator}

In order to optimize the neutron flux beam into the maximum output. Most of the fast neutron produce at the thermal column should be material that moderated using low atomic mass, does not produce moist, does not decompose in high radiation field and the neutron activation product produce should be short in half life. Commonly, in new world, the suitable material use to neutron moderator are $\mathrm{Al}, \mathrm{Al}_{2} \mathrm{CO}_{3}, \mathrm{Al}_{3} \mathrm{~F}$ and $\mathrm{D}_{2} \mathrm{O}$. The material that has low absorption cross section $\Sigma \mathrm{a}$ (barns) and high diffraction cross-section $\Sigma \mathrm{d}$ (barns). The moderation efficiency can be determined based on the moderation power (barns) and moderation ratio using Eq. (5) and (6) [24].

Moderation Power $=\xi \Sigma \mathrm{d}$

To become a good moderator material, each material should have high moderation ratio. The Eq. (6) below show the diffraction cross-section $\Sigma \mathrm{d}$ (barns) over absorption cross section $\Sigma$ a (barns).

Moderation ratio $=\xi \frac{\Sigma d}{\Sigma a}$ 


\subsection{Neutron Measurement}

\subsubsection{Gold foil activation method}

The neutron flux measurement is determined by using gold foil activation method that utilizes $197 \mathrm{Au}$ with neutrons to produce $198 \mathrm{Au}$ [25]. In this experiment, there are two types of samples being prepared which is pure $99.99 \%$ gold foil and Cadmium (Cd). The gold foil is used in this experiment because the gold foil will decay and emitting single gamma of well-known energy and the half-life of 2.81 days of gold is suitable for experimental purposes [25]. The cadmium well known as the thermal neutron filter will be used to cover gold foil for aiming separate the thermal and epithermal neutron flux. The data then analysed by using the specific equation for neutron activation analysis to obtain thermal neutron flux and epithermal neutron flux [26]. To determine the epithermal and thermal neutron flux, the count rate was converted into absolute foil activity by incorporating the detector efficiency by using the relation in Eq. (7) [27].

$A_{a b s}=\frac{C_{r}}{\eta_{d}}$

where $A_{a b s=}$ absolute foil activity (counts/s), $C_{r}=$ observed count rate (count/s), $\eta_{d}=$ detector relative efficiency. By finding the activity of bare gold foil and the activity of cadmium covered gold foil, the thermal flux was obtained by using Eq. (8) [26].

$\emptyset_{t h}=\frac{\rho\left(A_{a b s}-A_{c d}\right)}{m \Sigma_{a}\left(1-e^{-\lambda_{t i}}\right) e^{-\lambda_{t c}}}$

Where $A_{c d}=$ activity of cadmium covered gold foil, $\rho=$ density of the foil material $\left(\mathrm{gm} / \mathrm{cm}^{3}\right), m=$ weight of the foil (gm), $\Sigma_{a}=$ macroscopic thermal absorption cross-section $\left(\mathrm{cm}^{-1}\right), \lambda=$ decay constant of radioactive isotope formed during radiation $\left(\mathrm{s}^{-1}\right), t_{c}=$ cooling time $(\mathrm{s}), t_{i}=$ irradiation time $(\mathrm{s})$.

For gold, the response region that can absorb thermal neutron and epithermal neutron are in between $0.0015 \mathrm{eV}$ to $5.8 \mathrm{eV}$ and the cut-off energy of cadmium of $0.55 \mathrm{eV}$ was used to mark both thermal and epithermal neutron region. Therefore, the difference between the activity of bare gold foil and the cadmium covered gold foil, if both were irradiated in the same neutron flux under the same circumstances, is the activity caused by thermal neutron flux [28]. The ratio of thermal to epithermal fluxes was determined by cadmium ratio, which is defined by the Eq. (9) [26].

Cadmium ratio $=\frac{A_{a b s}}{A_{c d}}$

By using Eq. (8) and Eq. (9), the epithermal neutron flux can be calculated by the equations given below

$R_{c d}-1=\frac{\emptyset_{t h} \cdot \sigma_{t h}}{\theta 1526 b a r n}$

and,

$\emptyset_{e p i}=\theta \log \left(\frac{E_{2}}{E_{1}}\right)$ 
where $\emptyset_{t h}=$ thermal neutron cross-section (barns), $\theta=$ intermediate neutron flux density per unit lethargy, $\emptyset_{\text {epi }}=$ epithermal neutron flux (neutron. $\mathrm{cm}^{-2} \mathrm{~s}^{-1}$ ), $\mathrm{E}_{1}=0.5 \mathrm{eV}, \mathrm{E}_{2}=2 \mathrm{MeV}, \mathrm{I}_{\mathrm{r}}=$ resonance integral (1526 bams)

\subsubsection{Thermoluminescent dosimeter}

There are two types of TLD was used which is TLD-600 and TLD-700 for measuring gamma and neutron dose rate [28]. The use of TLD in this research is because of the advantage of a TLD that have the long-term storage of information data and have high sensitivity towards radiation [29]. TLD-600 could detect and sensitive to both neutron and photon such as gamma while TLD-700 only can sensitive to detect and measure photon only [30]. On the other hands, the use of TLD detector is convenient because the atomic density of LiF is definitely close to the human body. TLD detector also are being cheap and affordable compare to another detector use in the recent world market. Both TLD-600 and TLD-700 are determined to have practically been equipped to detect both thermal neutron and gamma -ray [31].

\subsection{BNCT Design and Modifications}

In this review, the arrangement, geometry and the design of the BNCT facility are being consider to optimize the thermal and epithermal neutron flux for successfully use as a beam in BNCT studies. There are several case studies that are being observed around the world in to order to find the feasibility in modifying the epithermal neutron and the thermal neutron at the research reactor for BNCT. The Table 1 shows the recommended value for BNCT by IAEA [14].

Table 1

The recommended value for BNCT by IAEA [14]

\begin{tabular}{lc}
\hline BNCT Beam Port Parameters & Recommended value \\
\hline Thermal neutron & $>10^{9}$ neutron. $\mathrm{cm}^{-2} \mathrm{~s}^{-1}$ \\
Gamma ray & $<10^{-13} \mathrm{Ycm}^{-2} \mathrm{~s}^{-1}$ \\
\hline
\end{tabular}

In Iran, the research regarding to BNCT has taken place at the Tehran research Reactor (TRR). TRR is a TRIGA type reactor, which has a thermal column with the cross section of $1.2 \mathrm{~m} \times 1.2 \mathrm{~m}$ and $3 \mathrm{~m}$ length. Initially, this thermal column has been filled with the graphite blocks, but for the BNCT purpose, they need to modified the thermal column to meet the thermal neutron beam criteria specified by IAEA. Figure 3 shows the thermal column of TRR before the modifications while the Figure 4 shows the thermal column after the modifications. 


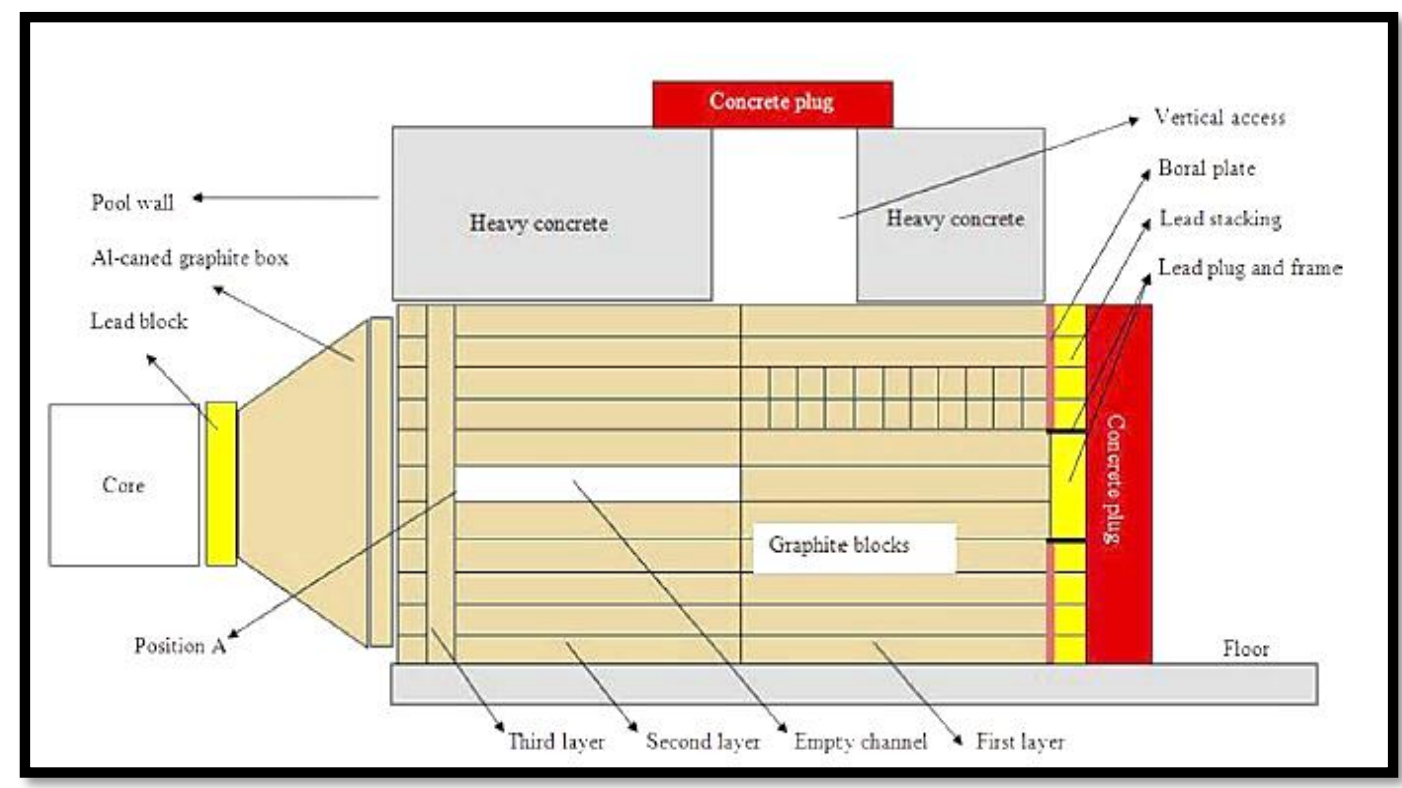

Fig. 3. Schematic diagram of thermal column before modifications [32]

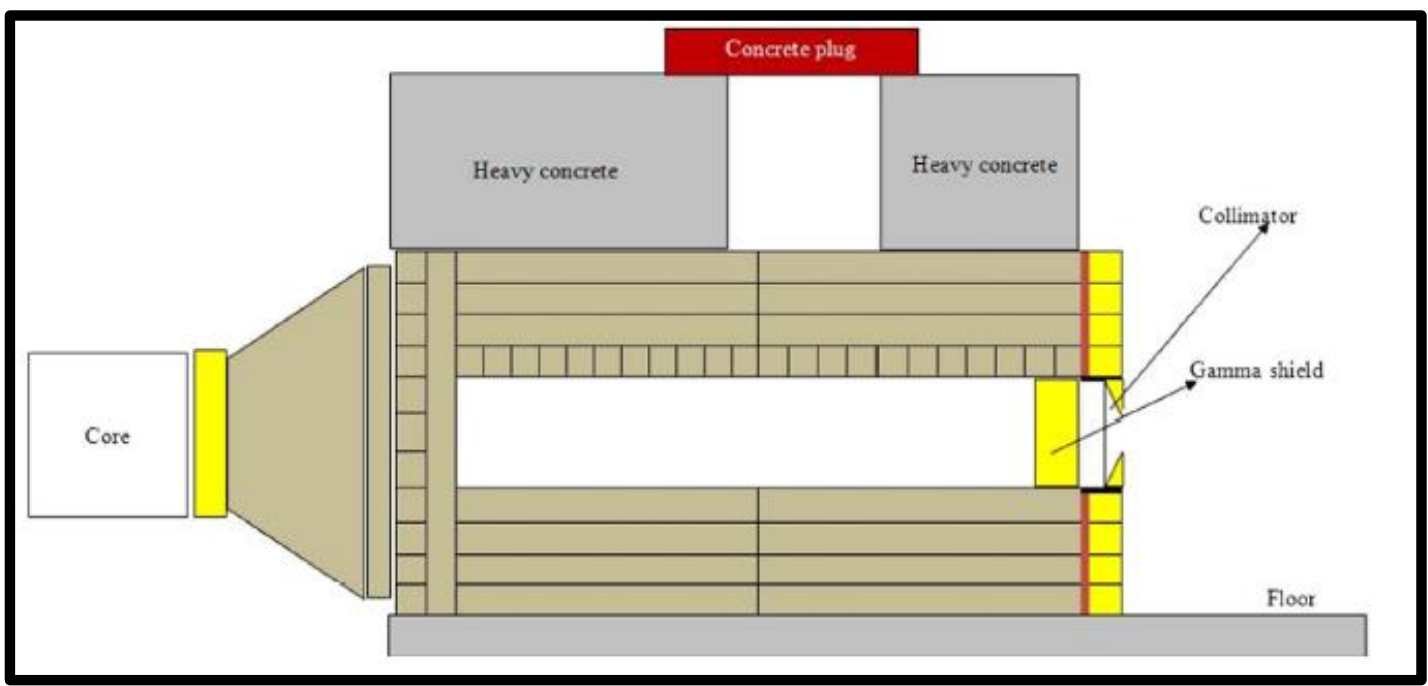

Fig. 4. Schematic diagram of thermal column after modifications [32]

The main objective of the modification of the thermal column at the TRR is achieve by rearrange the graphite blocks as figure above. Besides that, the gamma dose rate at the exit of the thermal column also being consider by placed the gamma shield before the collimator. Based on the measurement using neutron activation analysis and TLD-700 dosimeter, the modification of the thermal column for BNCT purpose at TRR had produce about $5.6 \times 10^{8}$ neutron. $\mathrm{cm}^{-2} \mathrm{~s}^{-1}$ of the thermal neutron beam and the gamma dose rate calculated was $0.57 \mathrm{Gyh}^{-1}$ while the cadmium ratio (CR) is 186 for gold foils. The advantages of this modification are minimal changes in the thermal column structure thus there are no disruption to the other TRR normal activities. Another advantage is the sample and the phantom for BNCT can be irradiated outside of the thermal column [32]. At the same time, the TRR researchers also found the potential to produce the epithermal neutron at the TRR based on the determination using MCNP (Monte Carlo N-Particle). For further research, the BSA (beam shaping assembly) has been designed and also modified to produce the epithermal neutron flux intensity required by IAEA for BNCT purpose. At first to optimize the thermal column to produce epithermal neutron as recommended by IAEA, the BSA design had been made by using MCNP4 code 
by considering that all the graphite blocks had been removed. The design of the BSA included the important parts such as thermal neutron filter, neutron reflector, neutron moderator and the gamma filter with the recommended of the suitable material use for BNCT by IAEA [32].

As show on the Figure 5, labelled 1 on the design shows the reactor core. The reactor core must be considered as a neutron source for the reactor. The number 2 on the design is a gamma filter in which the material use is lead block. This material was used to sufficiently filter the prompt gamma produce from the reactor core. Number 3, is an Aluminium canned graphite blocks and number 4 is the neutron moderator. In this design, the neutron moderator become the neutron parameter to be observe and the material use where are $\mathrm{Al}, \mathrm{Al}_{2} \mathrm{CO}_{3}, \mathrm{Al}_{3} \mathrm{~F}, \mathrm{MgF}_{2}, \mathrm{PbF}_{2}, \mathrm{Al} / \mathrm{AlF}_{3}$ alloy $\left(30 \% \mathrm{Al}, 70 \% \mathrm{AlF}_{3}\right)$, and Fluental alloy (30\% Al, 69\% $\mathrm{AlF}_{3}, 1 \% \mathrm{LiF}$ ) with different thickness. Number 5 on the BSA was the air that filled inside the collimator while the number 6 was the neutron reflector. The neutron reflector in this design is solid material in the form of $\mathrm{Pb}$ and PbF2 with different thickness. The gamma filter was being label as 7 with the use of bismuth material and the number 8 show that the thermal neutron filters that use $\mathrm{Cd}$ (cadmium) at the beginning and the end of the neutron moderator with $2 \mathrm{~mm}$ thickness. Number 9 on the design shows the phantom or sample place [32]. The result of the BSA design using simulation of MCNP4 shows that the epithermal neutron produce was $>1.0$ $\times 10^{9}$ neutron. $\mathrm{cm}^{-2} \mathrm{~s}^{-1}$ and the fast neutron produce was $>4 \times 10^{8}$ neutron. $\mathrm{cm}^{-2} \mathrm{~s}^{-1}$ that had proved the material use in this design was feasible enough. The use of thermal neutron filter also helps to give the higher value of epithermal neutron flux produce at the beam port as the thermal neutron was absorb by the cadmium sheets. According to Kasesaz et al., [32], the BSA design can be suggested for the thermal column of TRR with the use of $20 \mathrm{~cm}$ of aluminium as the best neutron moderator and the $2 \mathrm{~mm}$ cadmium sheet as thermal neutron filter that can highly produce about $>1.0 \times 10^{9}$ neutron. $\mathrm{cm}^{-2} \mathrm{~s}^{-1}$ of epithermal neutron beam. As summarize, the Table 2, 3 and 4 shows the design and modification for BNCT purpose by other researchers around the world to optimize by maximize slow neutron beam as required by IAEA. Table 2 shows the list of neutrons shielding material to shield neutron and photon for BNCT by a few researchers. Table 3 shows the neutron collimator material studied by a few researchers for BNCT purpose while Table 4 shows a list of neutron moderator material use by a few researchers for BNCT. All of the materials list from the table was useful in this research to design and modify the collimator for BNCT research facility.

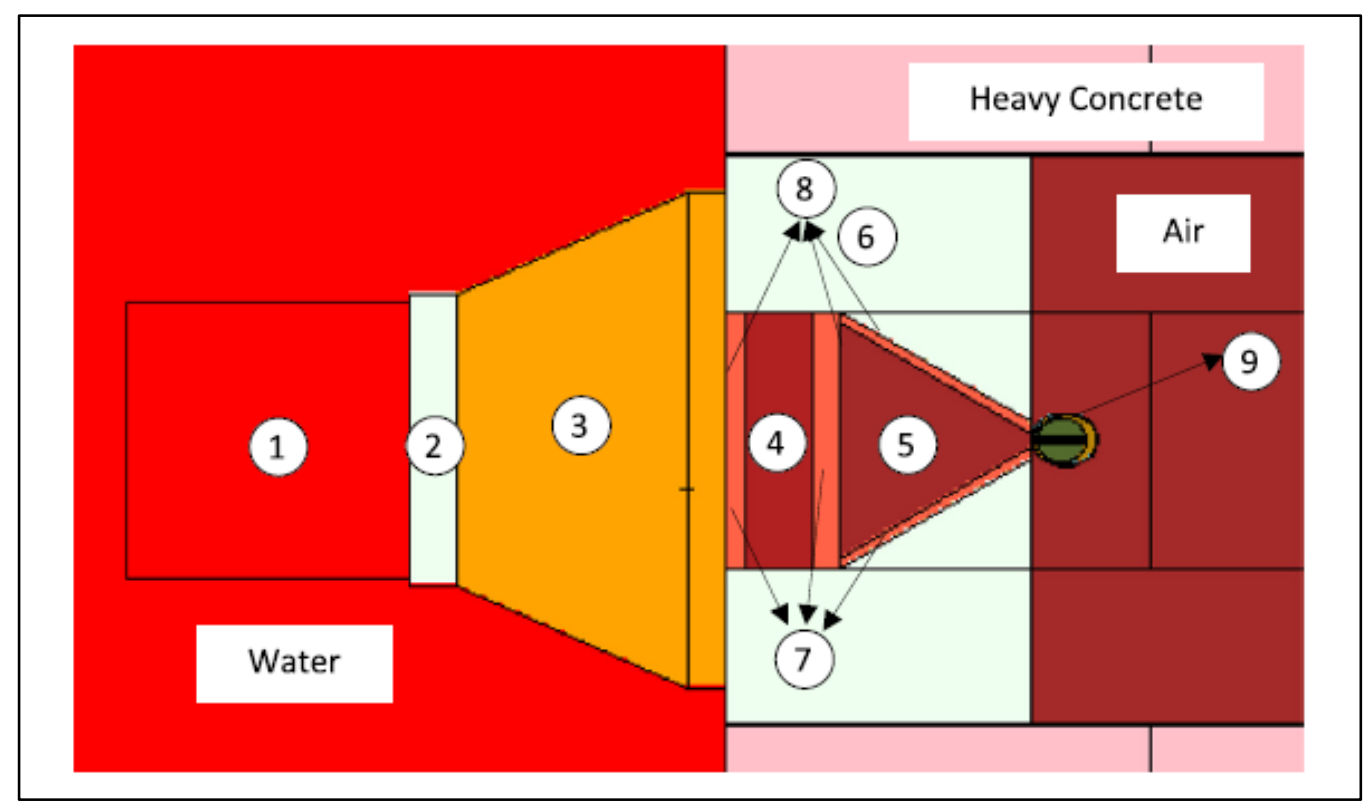

Fig. 5. MCNP geometry of BSA for epithermal neutron beam BNCT [32] 


\section{Table 2}

Neutron shielding material studied by a few researchers for BNCT purpose

\begin{tabular}{ll}
\hline Material & Researchers \\
\hline Bismuth & {$[33]$} \\
Fluental & {$[34]$} \\
Al, Cd, Fluental, Cd, Bi & {$[35]$} \\
$\mathrm{CF}_{2}$ & {$[36]$} \\
Heavy Water & {$[37]$} \\
Cadmium & {$[38]$} \\
\hline
\end{tabular}

\section{Table 3}

Neutron collimator material studied by a few researchers for BNCT purpose

\begin{tabular}{ll}
\hline Material & Researchers \\
\hline Lithium Polyethylene & {$[39]$} \\
Polyethylene & {$[40]$} \\
Li2CO3-PE & {$[35]$} \\
$\mathrm{Pb}$ & {$[36]$} \\
Nickel & {$[33]$} \\
Paraffin & {$[38]$} \\
\hline
\end{tabular}

\section{Table 4}

Neutron moderator material studied by a few researchers for BNCT purpose

\begin{tabular}{ll}
\hline Material & Researchers \\
\hline Aluminium & {$[33]$} \\
Heavy Concrete & {$[34]$} \\
Ordinary concrete, and borated polyethylene & {$[41]$} \\
6LiF Metathene & {$[42]$} \\
Polyethylene & {$[38]$} \\
\hline
\end{tabular}

\subsection{Measurement of Neutron Flux at The Thermal Column of Triga Mark-II Research Reactor Malaysia}

Initially, the measurement of the thermal neutron flux was conducted along the thermal column at $250 \mathrm{~kW}$. The thermal column was divided into 3 phases (Phase 1, Phase 2 and Phase 3 as display in Figure 6) so that an accurate measurement can be obtained by using gold foil activation method. This value was used as a benchmark for the neutron flux produced from the thermal column for BNCT purpose [44].

In the Phase 1 measurement, there are two main data to be analyses which is thermal neutron flux and epithermal neutron flux. From the data tabulated in Table 5, stringer G7 produced highest thermal neutron flux compared to E4, E10, L7, J10 and J4 with $7.42 \times 10^{11}$ neutron. $\mathrm{cm}^{-2} \mathrm{~s}^{-1}$ at the sample position of G19. In contrast, the lowest thermal neutron flux produced from this measurement was from the stringer $\mathrm{E} 10$ at the sample position of E18. The positioning of the stringer was one of the main factors that contribute to the production of thermal neutron flux. The stringer G7 was located at the center of the graphite thermal column and the closet stringer to the RTP core compared with E4, E10, L7, J10 and J4 [3]. In contrast, the position of stringer E10 (which is located above the reactor core) demonstrated the lowest thermal neutron flux due to the high volume of shielding material. Besides that, the epithermal neutron flux graph indicated that the highest result of epithermal neutron come from holes $\mathrm{G} 19$ with $1.16 \times 10^{11}$ neutron. $\mathrm{cm}^{-2} \mathrm{~s}^{-1}$ compare to the lowest result from stringers $L 7$. The location of stringer $L 7$ was nearest to the RTP moderator has produce 
the effect of thermalization. The interaction of the irradiated samples and coolant as an effect of thermalization has produced less epithermal neutron flux. The thermalization also affects the measured value of cadmium ratio from $L 7$ [3].

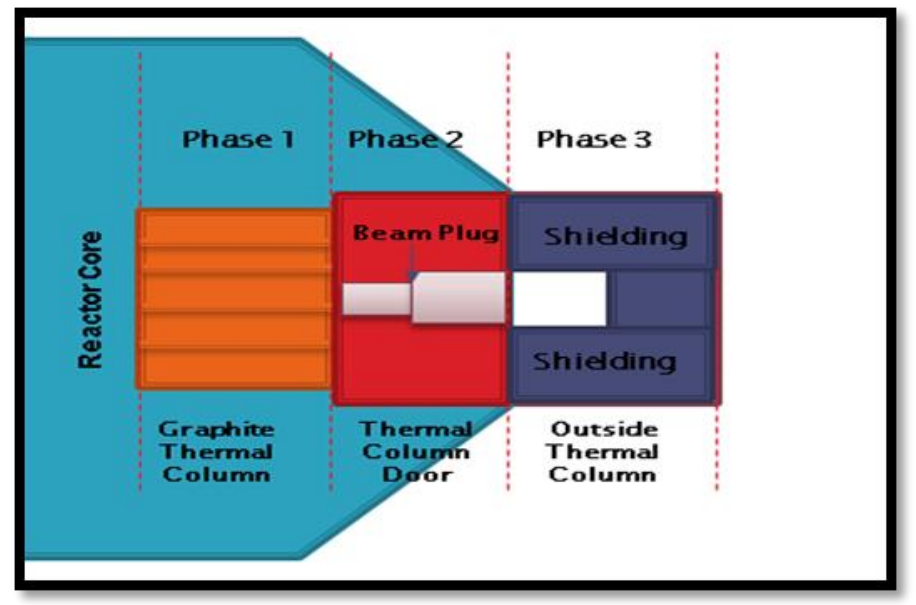

Fig. 6. Phase 1, Phase 2 and Phase 3 at the thermal column of RTP [3]

The statistically analysis using gold foil activation method can be used to determine the value of cadmium ratio. The cadmium ratio defines as the evaluation of activating nuclide of epithermal neutron compared to the thermal neutron [45]. The measurement of cadmium ratio is extensive in Phase 1 to determine the quality of the thermal and epithermal neutron produce from the stringer. The holes $\mathbf{L} 47$ from stringer L7 was significantly produced the highest cadmium ratio with 247.34 compared to other stringers. In contrast, most of the holes positioned next to the reactor core produced lower cadmium ratio compare to the holes positioned farther the reactor core. For example, holes G19 from stringer have lowest cadmium ratio due to positioning. This concludes the stringer L7 was had high active nuclide of epithermal neutron compared to the thermal neutron despite having lowest epithermal neutron flux and thermal neutron flux. To construct validity the gold foil activation measurement at Phase 1, the experiment results from this research was compared with measurement result using gold foil activation method from previous BNCT research at the thermal column at RTP [46].

Table 6 shows the comparison between the epithermal neutron flux and thermal neutron flux by using foil activation measurement from this research and previous research.

Based on Table 6, the data of the neutron flux measured by both researches from position G19, G24, G28 and G31 follows the decrease trend but there is some difference in terms of flux. The differences between reactor power operation during the measurement had affected the flux production for both epithermal neutron and thermal neutron. Thermal neutron produces were within the range of $10^{11}$ to $10^{10}$ neutron.cm-2s-1 for $250 \mathrm{~kW}$ [3]. The thermal neutron flux was flutter due to the reactor power noise on the neutron distribution that had effect on random neutron fluctuation [47]. The epithermal neutron flux and thermal neutron flux of Phase 3 and Phase 2 has been displayed on the Table 5 . The result shows that the stringers $\mathrm{G} 7$ produce the maximum production of thermal neutron flux of $3.62 \times 10^{7}$ neutron. $\mathrm{cm}^{-2} \mathrm{~s}^{-1}$ at the distance of $142 \mathrm{~cm}$. Basically, the neutron flux decreases linearly with the length. Thus, at the Phase 2, both thermal and epithermal neutron flux declining from the $10^{7}$ to the $10^{6}$ for thermal neutron. For the Phase 3 , the results of the thermal neutron flux decline about $25 \%$ from the $3.53 \times 10^{6}$ neutron.cm- ${ }^{2} \mathrm{~s}^{-1}$ and flutter back to 1.28 $\times 10^{6}$ neutron. $\mathrm{cm}^{-2} \mathrm{~s}^{-1}$ at the last sample (A6) in the distance of $283.9 \mathrm{~cm}$ from the thermal column. 
The fluctuation of the thermal neutron was occurred when there was air exposure along the Phase 3 and the interaction between them.

\section{Table 5}

Phase 1 measurement of epithermal neutron flux and thermal neutron flux using the gold foil activation method [3]

\begin{tabular}{llll}
\hline Stringers & Holes & $\begin{array}{l}\text { Thermal Neutron Flux, } \\
\text { neutron.cm } \mathrm{s}^{-1}\end{array}$ & $\begin{array}{l}\text { Epithermal Neutron Flux, } \\
\text { neutron.cm } \mathrm{s}^{-1}\end{array}$ \\
\hline E4 & E07 & $7.05 \times 10^{10}$ & $1.11 \times 10^{10}$ \\
& E09 & $2.34 \times 10^{10}$ & $3.10 \times 10^{8}$ \\
E12 & $2.24 \times 10^{10}$ & $2.18 \times 10^{9}$ \\
& E13 & $5.75 \times 10^{10}$ & $2.64 \times 10^{9}$ \\
& E16 & $1.04 \times 10^{10}$ & $1.33 \times 10^{9}$ \\
G7 & E18 & $1.35 \times 10^{9}$ & $6.61 \times 10^{7}$ \\
& G19 & $1.16 \times 10^{11}$ \\
& G24 & $7.42 \times 10^{11}$ & $2.30 \times 10^{9}$ \\
& G26 & $2.81 \times 10^{11}$ & $1.32 \times 10^{8}$ \\
J4 & G28 & $2.41 \times 10^{10}$ & $2.03 \times 10^{8}$ \\
& G31 & $1.47 \times 10^{10}$ & $1.73 \times 10^{8}$ \\
& J32 & $1.85 \times 10^{10}$ & $2.94 \times 10^{9}$ \\
J10 & J35 & $5.39 \times 10^{10}$ & $2.12 \times 10^{8}$ \\
& J37 & $8.31 \times 10^{10}$ & $1.81 \times 10^{8}$ \\
& J38 & $7.31 \times 10^{10}$ & $2.50 \times 10^{9}$ \\
L7 & J40 & $6.78 \times 10^{10}$ & $2.07 \times 10^{8}$ \\
& J43 & $1.63 \times 10^{10}$ & $1.13 \times 10^{8}$ \\
& L44 & $9.79 \times 10^{9}$ & $1.24 \times 10^{9}$ \\
& L46 & $2.10 \times 10^{10}$ & $3.65 \times 10^{7}$ \\
& L47 & $1.48 \times 10^{10}$ & $38 \times 10^{7}$ \\
\hline
\end{tabular}

Table 6

The measurement of thermal and epithermal by using gold foil activation method $[3,46]$

\begin{tabular}{lllll}
\hline Position & \multicolumn{2}{l}{ This research, neutron.cm cm $^{-2}$} & \multicolumn{2}{l}{ Munem (2007), neutron.cm ${ }^{-2} \mathrm{~s}^{-1}$} \\
\cline { 2 - 5 } & Thermal & Epithermal & Thermal & Epithermal \\
\hline G19 & $7.42 \times 10^{11}$ & $1.16 \times 10^{11}$ & $2.64 \times 10^{11}$ & $7.63 \times 10^{9}$ \\
G24 & $2.81 \times 10^{11}$ & $2.30 \times 10^{9}$ & $2.45 \times 10^{10}$ & $5.79 \times 10^{7}$ \\
G28 & $1.47 \times 10^{10}$ & $2.03 \times 10^{8}$ & $3.75 \times 10^{9}$ & $4.58 \times 10^{6}$ \\
G31 & $1.85 \times 10^{10}$ & $1.73 \times 10^{8}$ & $3.11 \times 10^{8}$ & $7.47 \times 10^{5}$ \\
\hline
\end{tabular}

The measurement of epithermal neutron flux also showed the flux decline along the distance. At the Phase 2, the initial flux of epithermal neutron was $5.91 \times 10^{6}$ neutron. $\mathrm{cm}^{-2} \mathrm{~s}^{-1}$ at the distance 142 $\mathrm{cm}$ from the graphite thermal column and continuously decrease to the $8.90 \times 10^{5}$ neutron.cm-2s-1 at the end of Phase 2. At the Phase 3, the last sample A6 produced only $3.89 \times 10^{4}$ neutron.cm-2s-1 which is about $99.34 \%$ reduces from the initial epithermal neutron flux from Phase 2. Technically, the epithermal neutron shows the gradually decline of flux along Phase 2 and Phase 3 without any fluctuation and follow the standard law of radiation and distance [3]. Both neutron thermal and epithermal neutrons flux decrease with the distance from $142 \mathrm{~cm}$ to $283.9 \mathrm{~cm}$ from graphite thermal column as the flux generally is exponentially decreasing with distance [48]. Based on Figure 7, from the Phase 1 to the Phase 2, the thermal and epithermal neutron flux is significantly reduced about 99.8\% for thermal neutron flux and $96.5 \%$ for epithermal neutron flux. The uses of graphite as a neutron moderator for the research reactor in Phase 1 become the main factor for the tremendously decreases of flux from the Phase 1 to the Phase 2. The properties of graphite that have higher thermal conductivity have increased the measurement of thermal and epithermal neutron flux at Phase 1 
[49]. Across the beam line, the thermal neutron flux was higher than epithermal neutron flux with $1.00 \times 10^{2}$ neutron. $\mathrm{cm}^{-2} \mathrm{~s}^{-1}$ difference because the thermal column itself produce are well known as the thermal neutron source at the RTP [50]. The aim of this measurement to clearly see the thermal and epithermal neutron across the beam line for the optimization purpose for the collimator [3].

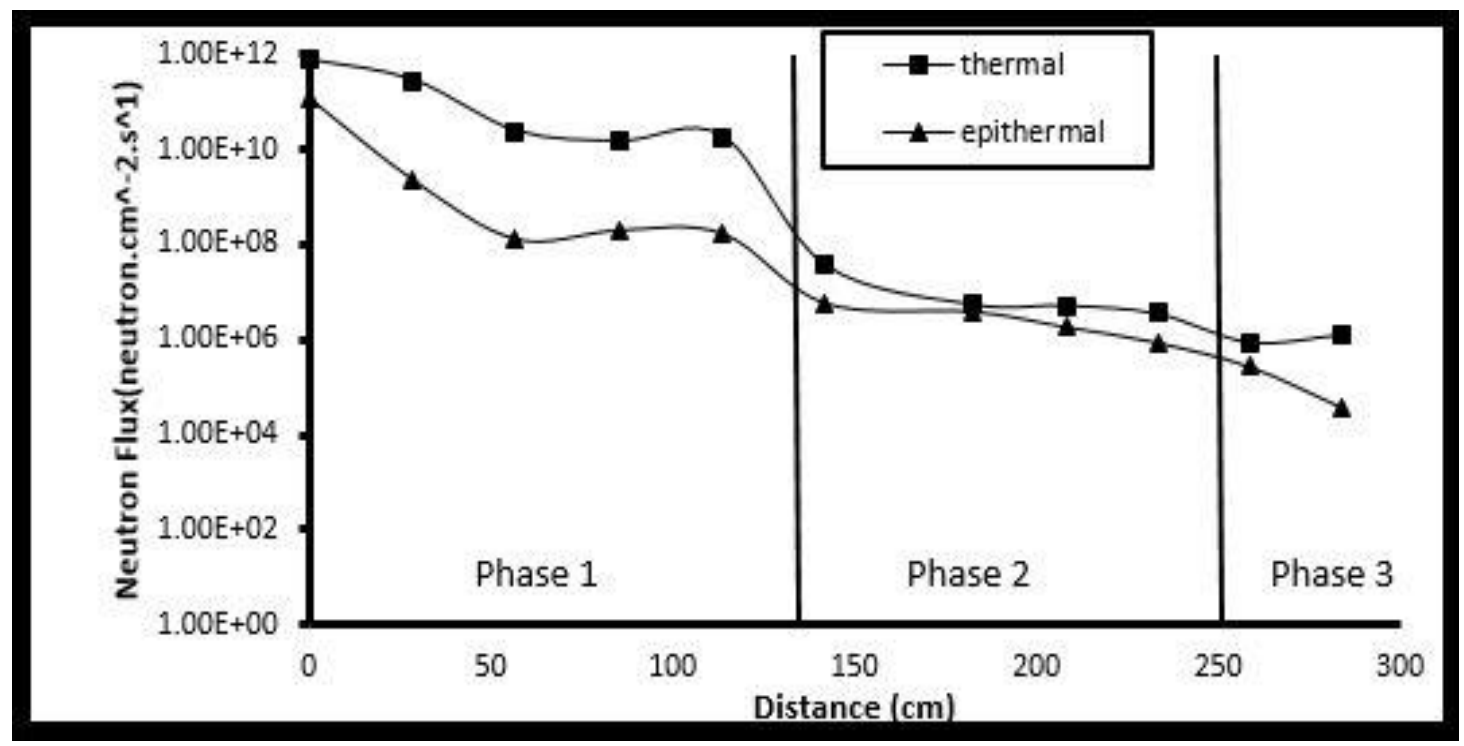

Fig. 7. The neutron flux measurement across the beam line for the Phase1, Phase 2 and Phase 3 [3]

\subsection{TLD-600 and TLD-700 measurements}

Table 7 shows the result of neutron and gamma at Phase 3 obtained from TLD-600 and TLD-700. Only Phases 3 available to use TLD as the TLD required shorten time to measure dose and to prevent any safety issues regarding radiation. The results revealed that the outside of the thermal column contains higher neutron than gamma. Therefore, at $250 \mathrm{~kW}$ experiment, the outside of the thermal column is safe with low gamma radiation [13]. By comparing both gold foil activation and TLD method, the neutron (mSv) at sample A5 is higher with TLD. As can be shown in Table 7, the gold foil activation measurement is significantly not synced with TLD experiment measurement due to different count rate. The TLD measurement is count right after the experiment been conducting while for the gold foil activation analysis the sample are count when the activity of the sample is low. The gap between the time of sample count for both experiments are affected the measurement [13]. In addition, the use of lead as a shielding in front the thermal column aperture during gold foil activation analysis has affected the neutron dose for TLD.

Table 7

The comparison between the measurement of neutron and gamma using TLD and gold foil activation method

\begin{tabular}{lllll}
\hline Sample & \multicolumn{2}{l}{$\begin{array}{l}\text { Gold foil activation } \\
\text { measurement }\end{array}$} & \multicolumn{2}{l}{$\begin{array}{l}\text { TLD-600 and TLD-700 } \\
\text { measurement }\end{array}$} \\
\cline { 2 - 6 } & $\begin{array}{l}\text { Neutron } \\
(\mathrm{mSv})\end{array}$ & $\begin{array}{l}\text { Gamma } \\
(\mathrm{mSv})\end{array}$ & $\begin{array}{l}\text { Neutron } \\
(\mathrm{mSv})\end{array}$ & $\begin{array}{l}\text { Gamma } \\
(\mathrm{mSv})\end{array}$ \\
\hline A5 & 3.00 & - & 4.20 & 0.25 \\
A6 & 4.20 & - & 2.38 & 0.27 \\
\hline
\end{tabular}


The thermal and epithermal neutron flux at the thermal column of Malaysia TRIGA MARK II reactor was successfully measured using two methods; gold foil activation and TLD. The purpose of this measurement is to explore the feasibility of the neutron source from the thermal column to be used for BNCT application. From the experiment conducted, the thermal column produces significantly higher thermal and epithermal flux at the stringers G7. Besides that, the data also proved that the thermal and epithermal flux decreases linearly with distance as the experiment are set up across the beam line on Phase 1, Phase 2 and Phase 3. This experimental data would be further used as a neutron source for the collimator design at the BNCT facility.

\section{Conclusion}

There is only a research reactor in Malaysia that was identified as an available neutron source for BNCT. The thermal column of RTP is determined to be a suitable place for BNCT purpose based on the early studied of BNCT. The measurement with the verification by experimental and simulation for the thermal neutron at the thermal column was precise that the availability of the thermal column of Malaysia RTP was sufficient enough for the development of BNCT as the quality and intensity of the neutron beam produced was well within a standard requirement for BNCT facility. The review on the material for BNCT collimator around the world benefit on specific material use for designing the ideal collimator and beam optimization. The material for designing collimator divide into neutron shielding materials, neutron moderator materials and neutron collimate material. This review characterizes explicitly those material based on their characteristic. This paper also reviews the current status of BNCT at the RTP with the measurement of the thermal neutron flux was conducted along the thermal column at $250 \mathrm{~kW}$. The thermal column of RTP was divided into 3 phases (Phase 1, Phase 2 and Phase 3 ) so that an accurate measurement can be obtained by using gold foil activation method. This value in the range of $1.0 \times 10^{6}$ neutron. $\mathrm{cm}^{-2} \mathrm{~s}^{-1}$ as a benchmark for the neutron flux produced from the thermal column. Thus, the aim of this paper is to review the thermal neutron beam by designing the external neutron collimator for the BNCT purpose so that the neutron flux obtained is within the range that set by the IAEA standard in the future. The purpose of this measurement is to explore the feasibility of the neutron source from the thermal column to be used for BNCT application. This experimental data would be further used in designing collimator and shielding for BNCT facility.

\section{Acknowledgement}

Special thanks to the Ministry of Higher Education and Universiti Malaysia Pahang for providing the financial support under the Postgraduate Research Grants Scheme (PGRS) Grant Scheme; Vot number: PGRS200304.

\section{References}

[1] Barth, R. F., P. Mi, and W. Yang. "Cancer Commun." (2018). https://doi.org/10.1186/s40880-018-0299-7

[2] Kim, Sunmi, Do-Kun Yoon, Han-Back Shin, Moo-Sub Kim, and Tae Suk Suh. "Analysis of therapeutic effectiveness attained through generation of three alpha particles in proton-boron fusion reaction based on Monte Carlo simulation code." Journal of Radioanalytical and Nuclear Chemistry 316, no. 3 (2018): 1059-1065. https://doi.org/10.1007/s10967-018-5813-5

[3] Shalbi, Safwan, Wan Norhayati Wan Salleh, Faridah Mohamad Idris, Muhammad Aliff Ashraff Rosdi, Muhammad Syahir Sarkawi, Nur Liyana Jamsari, and Nur Aishah Mohd Nasir. "Neutron measurement at the thermal column of the Malaysian Triga Mark II reactor using gold foil activation method and TLD." In IOP Conference Series: Materials Science and Engineering, vol. 298, no. 1, p. 012031. IOP Publishing, 2018. https://doi.org/10.1088/1757899X/298/1/012031 
[4] Wahyuni, Nur Setyo, and Yohannes Sardjono. "Assesment of Boron Neutron Capture Therapy (BNCT): Compact Neutron Generators." Indonesian Journal of Physics and Nuclear Applications 3, no. 2 (2018): 36-42.

[5] Bortolussi, S., N. Protti, M. Ferrari, I. Postuma, S. Fatemi, M. Prata, F. Ballarini et al. "Neutron flux and gamma dose measurement in the BNCT irradiation facility at the TRIGA reactor of the University of Pavia." Nuclear Instruments and Methods in Physics Research Section B: Beam Interactions with Materials and Atoms 414 (2018): 113-120. https://doi.org/10.1016/i.nimb.2017.10.023

[6] PATWARY, Md Mohsin. "Radiolysis of supercritical water (SCW) by radiations of different qualities: Formation of local, transient "acid spikes" at early times, and their consequences as potential sources of corrosion in proposed Generation IV SCW-cooled nuclear reactors. A Monte Carlo track chemistry simulation study." (2019).

[7] Kraft, Gerhard. "Tumor therapy with heavy charged particles." Progress in particle and Nuclear Physics 45 (2000): S473-S544. https://doi.org/10.1016/S0146-6410(00)00112-5

[8] Valda, A., D. M. Minsky, A. J. Kreiner, A. A. Burlon, and H. Somacal. "Development of a tomographic system for online dose measurements in BNCT (Boron Neutron Capture Therapy)." Brazilian journal of physics 35, no. 3B (2005): 785-788. https://doi.org/10.1590/S0103-97332005000500017

[9] Gohil, Chiragkumar J., and Malleshappa N. Noolvi. "Selective cancer treatment by Boron Neutron Capture Therapy (BNCT)-a review." Int. J. Pharm. Chem. Anal 2, no. 3 (2015): 136-138.

[10] Ono, Koji. "Prospects for the new era of boron neutron capture therapy and subjects for the future." Ther. Radiol. Oncol. 2 (2018): 40-46. https://doi.org/10.21037/tro.2018.09.04

[11] Nigg, David W. Neutron Sources and Applications in Radiotherapy-A Brief History, and Current Trends. No. INL/CON06-11615. Idaho National Laboratory (INL), 2006.

[12] Chen SN. Neutrons. In: Encyclopedia of Cancer and Society [Internet]. 2455 Teller Road, Thousand Oaks California 91320 United States: SAGE Publications, Inc.

[13] Solleh, Mohd, and Mohd Rafi. "Moderator, collimator and shielding studies for BNCT research at Malaysian Nuclear Agency." PhD diss., Universiti Sains Malaysia, 2016.

[14] IAEA. 2001. Current Status of Neutron Capture Therapy .Vienna: INTERNATIONAL ATOMIC ENERGY AGENCY; 2001. (TECDOC Series).

[15] Bosko, A., D. Zhilchenkov, and W. D. Reece. "GE PETtrace cyclotron as a neutron source for boron neutron capture therapy." Applied radiation and isotopes 61, no. 5 (2004): $1057-1062$. https://doi.org/10.1016/i.apradiso.2004.05.076

[16] Kankaanranta, Leena, Tiina Seppälä, Hanna Koivunoro, Kauko Saarilahti, Timo Atula, Juhani Collan, Eero Salli et al. "Boron neutron capture therapy in the treatment of locally recurred head and neck cancer." International Journal of Radiation Oncology* Biology* Physics 69, no. 2 (2007): 475-482. https://doi.org/10.1016/j.ijrobp.2007.03.039

[17] Bilski, P., and B. Obryk. "Thermoluminescent dosimetry at the IFJ Krakow." Properties of Semiconductor Nanostructures (Electronic Materials 4 (2006).

[18] Pohjola, M. "Biologically targeted treatment." (2009).

[19] Beddoe, A. H. "Boron neutron capture therapy." The British journal of radiology 70, no. 835 (1997): 665-667. https://doi.org/10.1259/bjr.70.835.9245876

[20] Akan, Zafer, Mehmet Türkmen, Tahir Çakır, İskender A. Reyhancan, Üner Çolak, Muhittin Okka, and Sahip Kızıltaş. "Modification of the radial beam port of ITU TRIGA Mark II research reactor for BNCT applications." Applied Radiation and Isotopes 99 (2015): 110-116. https://doi.org/10.1016/j.apradiso.2015.02.014

[21] Kreiner, Andres Juan, Javier Bergueiro, Daniel Cartelli, Matias Baldo, Walter Castell, Javier Gomez Asoia, Javier Padulo et al. "Present status of accelerator-based BNCT." Reports of Practical Oncology \& Radiotherapy 21, no. 2 (2016): 95-101. https://doi.org/10.1016/i.rpor.2014.11.004

[22] Allen, B. J., and A. Ralston. "Boron dose enhancement for 252Cf Brachytherapy." In Conference Proceedings, 7th International Symposium on Neutron Capture Therapy, vol. 1, pp. 271-274. 1996.

[23] Cacuci, Dan Gabriel, ed. Handbook of Nuclear Engineering: Vol. 1: Nuclear Engineering Fundamentals; Vol. 2: Reactor Design; Vol. 3: Reactor Analysis; Vol. 4: Reactors of Generations III and IV; Vol. 5: Fuel Cycles, Decommissioning, Waste Disposal and Safeguards. Vol. 1. Springer Science \& Business Media, 2010. https://doi.org/10.1007/978-0-387-98149-9

[24] Lamarsh, John R., and Anthony John Baratta. Introduction to nuclear engineering. Vol. 3. Upper Saddle River, NJ: Prentice hall, 2001.

[25] Albarqi, Mubarak, Raed Alsulami, Tayfun Akyurek, and Joseph Graham. "Neutron flux characterization of the beam port of the Missouri University of Science and Technology Reactor." Journal of Radioanalytical and Nuclear Chemistry 321, no. 1 (2019): 109-116. https://doi.org/10.1007/s10967-019-06561-2

[26] Shalbi, Safwan, Wan Norhayati Wan Salleh, Faridah Mohamad Idris, Muhammad Aliff Ashraff Rosdi, Muhammad Syahir Sarkawi, Nur Liyana Jamsari, and Nur Aishah Mohd Nasir. "Neutron measurement at the thermal column of the Malaysian Triga Mark II reactor using gold foil activation method and TLD." In IOP Conference Series: Materials 
Science and Engineering, vol. 298, no. 1, p. 012031. IOP Publishing, 2018. https://doi.org/10.1088/1757899X/298/1/012031

[27] Murata, Isao, Shingo Tamaki, Yuki Otani, Yuta Ohsawa, Yusuke Kashiwagi, Sachie Kusaka, and Fuminobu Sato. "Techniques to measure absolute neutron spectrum and intensity for accelerator based neutron source for BNCT." Plasma and Fusion Research 13 (2018): 2501007-2501007. https://doi.org/10.1585/pfr.13.2501007

[28] Yule, Herbert P. "Experimental Reactor Thermal-Neutron Activation Analysis Sensitivities." Analytical Chemistry 37, no. 1 (1965): 129-132. https://doi.org/10.1021/ac60220a034

[29] Ayyangar, K., A. R. Lakshmanan, Bhuwan Chandra, and K. Ramadas. "A comparison of thermal neutron and gamma ray sensitivities of common TLD materials." Physics in Medicine \& Biology 19, no. 5 (1974): 665. https://doi.org/10.1088/0031-9155/19/5/007

[30] Dong, S. L., T. C. Chu, G. Y. Lan, T. H. Wu, Y. C. Lin, and J. S. Lee. "Characterization of high-sensitivity metal oxide semiconductor field effect transistor dosimeters system and LiF: Mg, Cu, P thermoluminescence dosimeters for use in diagnostic radiology." Applied Radiation and Isotopes 57, no. 6 (2002): 883-891. https://doi.org/10.1016/S09698043(02)00235-X

[31] Miljanic, S., Maria Ranogajec-Komor, _. Kne_evi_, and B. Vekic. "Main dosimetric characteristics of some tissueequivalent TL detectors." Radiation protection dosimetry 100, no. 1-4 (2002): $437-442$. https://doi.org/10.1093/oxfordjournals.rpd.a005908

[32] Silva, Marcia Dutra R. "Ionizing radiation detectors." Evolution of Ionizing Radiation Research (2015): $189-209$. https://doi.org/10.5772/60914

[33] Kasesaz, Yaser, Hossein Khalafi, Faezeh Rahmani, Arsalan Ezzati, Mehdi Keyvani, Ashkan Hossnirokh, Mehrdad Azizi Shamami, and Sepideh Amini. "Design and construction of a thermal neutron beam for BNCT at Tehran Research Reactor." Applied Radiation and Isotopes 94 (2014): 149-151. https://doi.org/10.1016/i.apradiso.2014.08.004

[34] Fauziah, Nina, Andang Widiharto, and Yohannes Sardjono. "A conceptual design of neutron collimator in the thermal column of Kartini research reactor for in vitro and in vivo test of boron neutron capture therapy." JURNAL TEKNOLOGI REAKTOR NUKLIR TRI DASA MEGA 15, no. 2 (2015).

[35] Hawk, Andrew E., T. E. Blue, and J. E. Woollard. "A shielding design for an accelerator-based neutron source for boron neutron capture therapy." Applied radiation and isotopes 61, no. 5 (2004): 1027-1031. https://doi.org/10.1016/i.apradiso.2004.05.038

[36] Shaaban, Ismail. "Albarhoum and Mohamad 2015." Design calculation of an epithermal neutronic beam for BNCT at the Syrian MNSR using the MCNP4C code Progress in Nuclear Energy 78: $297-302$. https://doi.org/10.1016/i.pnucene.2014.10.005

[37] Monshizadeh, M., Y. Kasesaz, H. Khalafi, and S. Hamidi. "MCNP design of thermal and epithermal neutron beam for BNCT at the Isfahan MNSR." Progress in Nuclear Energy 83 (2015): $427-432$. https://doi.org/10.1016/j.pnucene.2015.05.004

[38] Durisi, E., A. Zanini, Claudio Manfredotti, F. Palamara, M. Sarotto, Lorenzo Visca, and U. Nastasi. "Design of an epithermal column for BNCT based on D-D fusion neutron facility." Nuclear Instruments and Methods in Physics Research Section A: Accelerators, Spectrometers, Detectors and Associated Equipment 574, no. 2 (2007): $363-369$. https://doi.org/10.1016/j.nima.2007.02.080

[39] Arif, M. A. "Study of Moderator (Collimator) Materials for Boron Neutron Capture Therapy (BNCT) Facilities at Thermal Column RTP." (2016).

[40] Faghihi, F., and S. Khalili. "Beam shaping assembly of a D-T neutron source for BNCT and its dosimetry simulation in deeply-seated tumor." Radiation Physics and Chemistry 89 (2013): 1-13. https://doi.org/10.1016/i.radphyschem.2013.02.003

[41] Pouryavi, Mehdi, S. Farhad Masoudi, and Faezeh Rahmani. "Radiation shielding design of BNCT treatment room for DT neutron source." Applied Radiation and Isotopes $99 \quad$ (2015): 90-96. https://doi.org/10.1016/i.apradiso.2015.02.016

[42] Sakurai, Yoshinori, Akira Sasaki, and Tooru Kobayashi. "Development of neutron shielding material using metathesis-polymer matrix." Nuclear Instruments and Methods in Physics Research Section A: Accelerators, Spectrometers, Detectors and Associated Equipment 522, no. $3 \quad$ (2004): $455-461$. https://doi.org/10.1016/j.nima.2003.11.420

[43] Sakurai, Yoshinori, Akira Sasaki, and Tooru Kobayashi. "Development of neutron shielding material using metathesis-polymer matrix." Nuclear Instruments and Methods in Physics Research Section A: Accelerators, Spectrometers, Detectors and Associated Equipment 522, no. $3 \quad$ (2004): $455-461$. https://doi.org/10.1016/j.nima.2003.11.420

[44] Burn, K. W., V. Colli, G. Curzio, F. d'Errico, G. Gambarini, G. Rosi, and L. Scolari. "Characterisation of the TAPIRO BNCT epithermal facility." Radiation protection dosimetry 110, no. 1-4 (2004): 645-649. https://doi.org/10.1093/rpd/nch161 
[45] Chen, Chien-Yi, Yuan-Yaw Wei, Sheng-Pin ChangLai, and Lung-Kwang Pan. "Bromine and iodine in Chinese medical herbs determined via epithermal neutron activation analysis." Journal of radioanalytical and nuclear chemistry 257, no. 2 (2003): 405-410. https://doi.org/10.1023/A:1024708518645

[46] Munem, Eid Abdel, and Eid Mahmoud. "Neutron flux measurements with Monte Carlo verification at the thermal column of a Triga mark II reactor: Feasibility study for a BNCT facility." (2007).

[47] Ricker, C. W., D. N. Fry, E. R. Mann, and S. H. Hanauer. "Investigation of Negative Reactivity Measurements by Neutron Fluctuation Analysis." In Proc. Symp. on Noise AnalYSis in Nucl. Systems, p. 171.1963. https://doi.org/10.1016/0368-3230(64)90033-3

[48] Rosdi, Muhammad Aliff Ashraff, Pei Sean Goh, Faridah Idris, Safwan Shalbi, Muhammad Syahir Sarkawi, Nur Syazwani Mohd Ali, Nur Liyana Jamsari, Ahmad Syafiq Ramli, and Azraf Azman. "Neutron and gamma ray fluences measurement at radial Beam Port 1 of TRIGA MARK II PUSPATI research reactor." In IOP Conference Series: Materials Science and Engineering, vol. 298, no. 1, p. 012033. IOP Publishing, 2018. https://doi.org/10.1088/1757899X/298/1/012033

[49] Krupa, I., I. Novák, and I. Chodák. "Electrically and thermally conductive polyethylene/graphite composites and their mechanical properties." Synthetic metals 145, no. 2-3 (2004): $245-252$. https://doi.org/10.1016/i.synthmet.2004.05.007

[50] Shalbi, Safwan, Wan Norharyati Wan Salleh, Muhammad Aliff Ashraff Rosdi, and Faridah Mohamad Idris. "Optimization and designing collimator for boron neutron capture therapy at the thermal column of RTP." In IOP Conference Series: Materials Science and Engineering, vol. 555, no. 1, p. 012017. IOP Publishing, 2019. https://doi.org/10.1088/1757-899X/555/1/012017 